\title{
Compare between the complication of simultaneous and staged bilateral knee replacement at king abdulaziz medical city (kamc) - riyadh
}

\begin{abstract}
Introduction: Total Knee replacement is a procedure commonly performed for degenerative joint disorder, e.g. osteoarthritis and rheumatoid arthritis. It is considered to be the most common and successful joint replacement. There will be an increase demand for the bilateral total knee replacement in the future due to increase of aging population and the indication to perform the surgery. There are controversies in the post surgical complication following simultaneous and staged bilateral total knee replacement; many studies have shown an increase in the mortality rate with simultaneous bilateral knee replacement. Other studies are showing evidence that suggest that there is no difference in the complication between simultaneous and staged bilateral total knee replacement.
\end{abstract}

Methods: The study included 84 simultaneous BTKR, 110 staged BTKR (with time interval between the two 3 to 6 months) and 51 UTKR whom performed the surgery between January 2000 and August 2014. The collected data included demographic data, surgical data, complications and length of stay. We also have collected some variables of interest; Demographic (Gender, Age and Weight), Type of surgery (study groups), Hospital stay, Duration of procedure, Amount of bleeding, hemoglobin level before and after the operation and type of anesthesia.

Results: We have a total of 245 patients. 110 (44.9\%) underwent staged bilateral total knee replacement (BTKR), 84 underwent simultaneous bilateral total knee replacement (BTKR), and 51 of did the surgery on only one. The results showed that out of the 245, 194(79.18\%) have not developed any complications, $62(73.81 \%)$ were simultaneous BTKR, $89(80.91 \%)$ of the staged BTKR and only $43(84.31 \%)$ were bilateral TKR. $43(17.55 \%)$ have developed minor complications which includes, Infection, UTI, Infected knee post operation or pulmonary complication other than pulmonary embolism. 18(21.43\%) underwent simultaneous BTKR, $17(15.45 \%)$ for the staged BTKR and $8(15.69 \%)$ for the unilateral TKR. Only 8 patients have developed major complication $(3.27 \%)$ of the general population. $4(4.76 \%)$ of the simultaneous BTKE and $4(3.64 \%)$ of the staged BTKR. None of the unilateral has developed major complication. We found a mean $\pm \mathrm{SE}$ of the total days of hospital stay for all the groups was $12.58 \pm$. 52, for the simultaneous BTKR patients, the mean \pm SE of hospital stay was $11.05 \pm 0.39$ days, and for the staged was $16.19 \pm 1.31$ days and $9.96 \pm 0.58$ days, with a $\mathrm{p}$ value $<.0001$

Conclusion: We can say that simultaneous TKR is a save procedure to be performed especially in hospital where there is long waiting list as well difficulty of having elective bed as in our hospital. And we found out that patients whom underwent staged BTKR stayed at the hospital more than patients whom underwent simultaneous BTKR.

Keywords: Total Knee replacement; Complication; Simultaneous bilateral total knee replacement; Staged bilateral total knee replacement
Volume 4 Issue 3 - 2016

\author{
Muath Abu-Abah,' Wazzan Aljuhani,' 'Hanadi \\ Al-Qahtani ${ }^{2}$ \\ 'King Saud Bin Abdulaziz University for Health Sciences, Saudi \\ Arabia \\ ${ }^{2}$ Clinical Research Coordinator, King Abdullah International \\ Medical Research Center, Saudi Arabia
}

Correspondence: Muath Abu-Abah, Intern, King Saud Bin Abdulaziz University for Health Sciences, Saudi Arabia Email dr.abuadah@hotmail.com

Received: January 21, 2016 | Published: February 15, 2016

\section{Abbreviation}

BTKR: Bilateral Total Knee Replacement; UTKR: Unilateral Total Knee Replacement; TKA: Total Knee Replacement; ICU: Intensive Care Unite

\section{Introduction}

Total Knee replacement is a procedure commonly performed for degenerative joint disorder, e.g. osteoarthritis and rheumatoid arthritis. It is considered to be the most common and successful joint replacement. ${ }^{1}$ It is expected that there will be an increase demand for a bilateral total knee replacement in the future due to increase of aging population and the indication to the surgery1. Generally, the procedure has a good functional outcome to all patients. However, a patient who is either present with pain in one knee or complaining of pain in both knees, which could result in sever disability. When both knees are affected, the patient and the surgeon must decide to either operate on both knee in one procedure with one admission and one anesthesia (Simultaneous bilateral total knee replacement), or they perform the surgery in two different operations, 2 separate anesthesia and 2 periods of rehabilitation (staged bilateral total knee replacement).

There have been controversies in the post-surgical complications following simultaneous and staged bilateral total knee replacement. In fact, many studies have shown an increase in the mortality rate with simultaneous bilateral knee replacement. ${ }^{1-3}$ whereas, Other studies are showing evidence that suggest that there is no difference in the complication between simultaneous and staged bilateral total knee 
replacement. ${ }^{3}$ On the other hand, levy et al. ${ }^{4}$ found out that in-hospital and late infection with simultaneous bilateral total knee replacement in lower when compared with staged, which increases the morbidity, mortality rates and total hospital stay. ${ }^{5}$ Some surgeons think that postsurgical complications are age dependent, where patients who are older than 75 years old are prone to more complicated complications. The most significant benefit of simultaneous bilateral total knee replacement is the decrease of cost for the institution, the use of only one anesthesia and decreases the length of the patients' hospital stay. Regarding the need for blood transfusion, there is a need of 1.5 -fold greater with simultaneous bilateral knee replacement ${ }^{6}$ Simultaneous bilateral knee replacement is considered, according to many studies, to be a safer procedure and to have a lower rate of complications incidents when compared to a staged BTKR. ${ }^{2,7,8}$ When reviewing the effect of the type of anesthesia on the outcome, we found out that neuraxial anesthesia is associated with lower rate of blood transfusion and mortality in BTKR.

In this study, we attempted to compare between simultaneous bilateral knee replacement, staged bilateral knee replacement and unilateral knee replacement in terms of post operation complications, total blood loss, blood transfusion, ICU admission, type of anesthesia, duration of the operation, hemoglobin before and after the surgery, length of hospital stay and the usage of drain. Moreover, we tried to determine the factors that increase the risk of any complication.

The aim of this study is to identify and compare the complications of simultaneous bilateral total knee replacement (BTKR), staged bilateral total knee replacement (BTKR) and unilateral total knee replacement (UTKR) in terms of morbidity and quality of life and to look for any risk that might contribute to the complication.

\section{Materials and methods}

We carried out a retrospective study, where we reviewed charts of all the adult patients who underwent simultaneous bilateral total knee replacement, staged bilateral total knee replacement and unilateral total knee replacement of both genders at KAMC between 2005 until 2014. The patients were identified from database of orthopedic department at King Abdulaziz Medical City (KAMC), Riyadh, Saudi Arabia. We followed up with the patients until the day of their discharge from hospital. The complications during surgery and post-operative period were recorded from the Medical Charts. The collected data included demographic data, surgical data, complications and length of stay. Some variables of interest have also been collected: Demographic (Gender, Age and Weight), Type of surgery (study groups), Hospital stay, Duration of procedure, Amount of bleeding, Complications, Length of stay, hemoglobin level before and after the operation and type of anesthesia.

All the patients who have had bilateral knee replacement, and: (1) Were Diagnosed with osteoarthritis; (2) Younger than age 70; (3) Their body mass index is $33 \mathrm{~kg} / \mathrm{m} 2$ or less; and (4) Had the surgery between January 2005 and July 2014, have been included in this study. All the patients who do not meet these criteria were excluded.

Raw data of key study variables were inspected for missing values in order to identify the extent and the pattern of missingness prior to any statistical analyses. In order to accomplish this task, all key variables were checked and summarized in terms of the frequency and the percent of missing values. Based on the magnitude and patterns of the missingness, an appropriate imputation technique was utilized. Variables that include extreme values which are considered outliers but yet are considered clinically acceptable were considered for analysis. In this study, one strategy used for handling outliers was to run the analysis with and without outliers to quantify the effect of outliers on the results. Robust measures, such as trimmed means or medians for central tendency, were also another strategy used in this study.

The demographics characteristics of patients were summarized and reported using descriptive statistics. Interval variables, age and weight, were compared between study groups by using t-test. Results were reported as mean, standard error and corresponding p-value. Categorical variables such as gender, anesthesia were compared between study groups by using chi-square test. Results were reported in terms of proportions, percent, and p-value. The length of hospital stay, drop in $\mathrm{Hb}$, amount of bleeding, and amount of blood transfusion were compared across study groups using ANOVA. All analyses were conducted using SAS version 9.2 (SAS Institute Inc., Cary, NC).

\section{Results}

We have a total of 245 patients. $110(44.9 \%)$ underwent staged bilateral total knee replacement (BTKR), 84 underwent simultaneous bilateral total knee replacement (BTKR), and 51 of did the surgery on only one. We have notice female dominance in the patients whom underwent BTKR and UTKR (210 patients - 85.71\%) of the total patients are female. $14.29 \%$ were male. The data shows that patients almost always went for BTKR (Table 1).

More than half of the patients underwent the procedure under epidural and spinal anesthesia (74.85\%), the rest preferred to go for general anesthesia (Table 1).

The age distribution between the types, 60.5 was the mean age for simultaneous and staged BTKR patients and 59 for unilateral TKR patients. For the weight, 85 was the mean for staged BTKR, and 81 for simultaneous BTKR and unilateral TKR (Table 1).

Five patients who underwent BTKR developed pulmonary embolism, three of them performed staged BTKR and two of simultaneous. One of the two simultaneous required intensive care admission. Two patients who performed BTKR, one was for simultaneous and the other for a stage, developed deep venous thrombosis. Eight patients returned to the hospital with infected knee, three of them underwent simultaneous BTKR, two underwent staged BTKR and three did UTKR. 12 patients developed UTI, 3 simultaneous BTKR, 4 staged BTKR and 5 unilateral TKR. Only 2 patients have developed pulmonary complication other than PE, one from the staged BTKR group and the other one from the unilateral TKR. We had one patient with cardiology complication (Table 2).

Complications were classified into 3 main groups, none, minor and major. Out of the 245, 194(79.18\%) have not develop any complication, 62(73.81\%) were simultaneous BTKR, 89(80.91\%) of the staged BTKR and only $43(84.31 \%)$ were bilateral TKR. $43(17.55 \%)$ developed minor complication, which includes Infection or UTI or Infected knee post-operation, or pulmonary complication other than PE. 18(21.43\%) underwent simultaneous BTKR, $17(15.45 \%)$ for the staged BTKR and $8(15.69 \%)$ for the unilateral TKR. Only 8 patients have developed major complications $(3.27 \%)$ of the general population. $4(4.76 \%)$ of the simultaneous BTKE and $4(3.64 \%)$ of the staged BTKR. None of the unilateral has developed major complications (Table 3 ).

We had only one patient who needed the admission to the Intensive Care Unit (ICU), she was form the simultaneous group (Table 3). 
Table I Demographic Characteristics of the Study Cohort

\begin{tabular}{|c|c|c|c|c|c|}
\hline Variables & $\begin{array}{l}\text { Overall } \\
\mathrm{n}=245\end{array}$ & $\begin{array}{l}\text { Simultaneous } \\
n=84\end{array}$ & $\begin{array}{l}\text { Staged } \\
n=110\end{array}$ & $\begin{array}{l}\text { Unilateral } \\
n=5 \text { I }\end{array}$ & p-value \\
\hline \multicolumn{6}{|l|}{ Gender n (\%) } \\
\hline Female & $210(85.71)$ & $70(83.33)$ & $94(85.45)$ & $46(90.20)$ & \\
\hline Male & $35(14.29)$ & $14(16.67)$ & $16(14.55)$ & $5(9.80)$ & $0.540 *$ \\
\hline Age mean \pm SE & $60.35 \pm 0.39$ & $61.14 \pm 0.56$ & $60.01 \pm 0.66$ & $59.80 \pm 0.77$ & $0.345^{* *} *$ \\
\hline $\begin{array}{l}\text { Weight mean } \pm \text { SE } \\
\text { Anesthesia } \mathbf{n}(\%)\end{array}$ & $83.13 \pm 0.79$ & $81.30 \pm 1.33$ & $85.26 \pm 1.23$ & $81.52 \pm 1.56$ & $0.052^{* *}$ \\
\hline Epidural & $126(51.85)$ & $33(40.24)$ & $56(50.91)$ & $37(72.55)$ & \\
\hline General & $94(38.68)$ & $44(53.66)$ & $43(39.09)$ & $7(13.73)$ & $0.0003 *$ \\
\hline Other & $23(9.47)$ & $5(6.10)$ & $\mathrm{II}(10.0)$ & $7(13.73)$ & \\
\hline Missing & 2 & - & - & - & \\
\hline
\end{tabular}

*Chi-square test

**ANOVA

Table 2 Distribution of Surgical Complications across Study Groups

\begin{tabular}{|c|c|c|c|c|c|}
\hline Complications & $\begin{array}{l}\text { Overall } \\
n=245\end{array}$ & $\begin{array}{l}\text { Simultaneous } \\
n=84\end{array}$ & $\begin{array}{l}\text { Staged } \\
\text { (Right \& Left) } n=\mid 10\end{array}$ & $\begin{array}{l}\text { Unilateral } \\
n=5 \text { I }\end{array}$ & p-value \\
\hline \multicolumn{6}{|l|}{ DVT n (\%) } \\
\hline Yes & $2(0.82)$ & $\mathrm{I}(\mathrm{I} .19)$ & $\mathrm{I}(0.9 \mathrm{I})$ & 0 & \multirow{2}{*}{$1.00 *$} \\
\hline No & 243(99.18) & $83(98.81)$ & $109(99.09)$ & $5 I(100.0)$ & \\
\hline \multicolumn{6}{|l|}{ PE n (\%) } \\
\hline Yes & $5(2.04)$ & $2(2.38)$ & $3(2.73)$ & 0 & \multirow{2}{*}{$0.718 * *$} \\
\hline No & $240(97.96)$ & $82(97.62)$ & $107(97.27)$ & $5 \mathrm{I}(100.0)$ & \\
\hline \multicolumn{6}{|c|}{ Post-Operative Infection of the Knee n (\%) } \\
\hline Yes & $8(3.27)$ & $3(3.57)$ & $2(1.82)$ & $3(5.88)$ & \multirow{2}{*}{$0.419 * *$} \\
\hline No & $237(96.73)$ & $81(96.43)$ & $108(98.18)$ & $48(94.12)$ & \\
\hline \multicolumn{6}{|l|}{ UTI n (\%) } \\
\hline Yes & $12(4.90)$ & $3(3.57)$ & $4(3.64)$ & $5(9.80)$ & \multirow{2}{*}{$0.227 * *$} \\
\hline $\begin{array}{l}\text { No } \\
\text { Pulmonary }\end{array}$ & $233(95.10)$ & $81(96.43)$ & $106(96.36)$ & $46(90.20)$ & \\
\hline \multicolumn{6}{|c|}{ (Other than PE ) n (\%) } \\
\hline Yes & $2(0.82)$ & $0(0)$ & $\mathrm{I}(0.9 \mathrm{I})$ & $\mathrm{I}(1.96)$ & \\
\hline No & $243(99.18)$ & $84(100)$ & 109(99.09) & $50(98.04)$ & \\
\hline \multicolumn{6}{|c|}{ Cardiological n (\%) } \\
\hline Yes & $\mathrm{I}(0.4 \mathrm{I})$ & $83(34.02)$ & $110(100)$ & $5 I(100)$ & \multirow{2}{*}{$0.55 \mathrm{I} * *$} \\
\hline No & $244(99.59)$ & $\mathrm{I}(\mathrm{I} .19)$ & $0(0)$ & $0(0)$ & \\
\hline \multicolumn{6}{|l|}{ Febrile n (\%) } \\
\hline Yes & $12(4.92)$ & $5(6.02)$ & $7(6.36)$ & $0(0)$ & \multirow{2}{*}{$0.166 * *$} \\
\hline No & $232(95.08)$ & $78(93.98$ & $103(93.64)$ & $5 I(100)$ & \\
\hline
\end{tabular}

*Chi-square test

**Fischer exact test

Table 3 Surgical Complications Rate Comparison across Study Groups

\begin{tabular}{|c|c|c|c|c|c|}
\hline Variables & Overall $n=245$ & $\begin{array}{l}\text { Simultaneous } \\
\mathrm{n}=\mathbf{8 4}\end{array}$ & $\begin{array}{l}\text { Staged (Right \& Left) } \\
n=\mid 10\end{array}$ & $\begin{array}{l}\text { Unilateral } \\
n=5 \text { I }\end{array}$ & p-value \\
\hline None n (\%)* & 194(79.18) & $62(73.8 I)$ & $89(80.91)$ & $43(84.31)$ & \\
\hline $\begin{array}{l}\text { Minor Complications n (\%)* } \\
\text { Major Complications } \mathrm{n}(\%)^{*}\end{array}$ & $\begin{array}{l}43(17.55) \\
8(3.27)\end{array}$ & $\begin{array}{l}18(21.43) \\
4(4.76)\end{array}$ & $\begin{array}{l}17(15.45) \\
4(3.64)\end{array}$ & $\begin{array}{l}8(15.69) \\
0(0)\end{array}$ & $0.443^{* *}$ \\
\hline
\end{tabular}

*Chi-square test

**Fischer exact test

Table 4 Comparison of LOS, Drop in Hemoglobin across Study Groups

\begin{tabular}{|c|c|c|c|c|c|}
\hline & $\begin{array}{l}\text { Overall } n=245 \\
\text { mean } \pm \text { SE }(95 \% \mathrm{Cl})\end{array}$ & $\begin{array}{l}\text { Simultaneous } n=84 \\
\text { mean } \pm \text { SE }(95 \% \mathrm{CI})\end{array}$ & $\begin{array}{l}\text { Staged } n=I I 0 \\
\text { mean } \pm \text { SE }(95 \% \mathrm{CI})\end{array}$ & $\begin{array}{l}\text { Unilateral } \\
\text { mean } \pm \text { SE (95\% Cl) }\end{array}$ & p-value $* *$ \\
\hline LOS (days) (mean \pm SE) & $\begin{array}{l}12.58 \pm 0.52 \\
(I 1.55-13.62)\end{array}$ & $\begin{array}{l}11.05 \pm 0.39 \\
(10.26-11.84)\end{array}$ & $\begin{array}{l}16.19 \pm 1.31 \\
(13.57-18.80)\end{array}$ & $\begin{array}{l}9.96 \pm 0.58 \\
(8.78-11.13)\end{array}$ & $<.0001$ \\
\hline $\begin{array}{l}\text { Duration of Operation (hours) } \\
\text { (mean } \pm S E \text { ) }\end{array}$ & $\begin{array}{l}2.75 \pm 0.08 \\
(2.59-2.91)\end{array}$ & $\begin{array}{l}2.14 \pm 0.06 \\
(2.01-2.27)\end{array}$ & $\begin{array}{l}4.0 \pm 0.13 \\
(3.72-4.27)\end{array}$ & $\begin{array}{l}2.01 \pm 0.09 \\
(1.82-2.21)\end{array}$ & $<.0001$ \\
\hline $\begin{array}{l}\text { Drop in } \mathbf{H b}^{*} \\
\text { (mean } \pm \mathrm{SE})\end{array}$ & $\begin{array}{l}28.64 \pm 0.98 \\
(26.69-30.58)\end{array}$ & $\begin{array}{l}26.0 \pm 1.12 \\
(23.79-28.24)\end{array}$ & $\begin{array}{l}31.12 \pm 2.13 \\
(26.86-35.37)\end{array}$ & $\begin{array}{l}30.21 \pm 1.97 \\
(26.24-34.18)\end{array}$ & 0.053 \\
\hline $\begin{array}{l}\text { Blood Transfusion } \\
\text { Units) (mean } \pm S E)\end{array}$ & $\begin{array}{l}1.09 \pm 0.09 \\
(0.89-1.29)\end{array}$ & $\begin{array}{l}0.527 \pm 0.09 \\
(0.33-0.71)\end{array}$ & $\begin{array}{l}2.28 \pm 1.78 \\
(1.89-2.67)\end{array}$ & $\begin{array}{l}0.352 \pm 0.12 \\
(0.11-0.59)\end{array}$ & $<.0001$ \\
\hline
\end{tabular}

*Drop in $\mathrm{Hb}$ : pre $\mathrm{Hb}$ - post $\mathrm{Hb}$

**Generalized Linear Model

LOS: length of hospital stay; Hb: Hemoglobin

DVT: Deep Venous Thrombosis; PE: Pulmonary Embolism; UTI: Urinary Tract infection.

Citation: Abu-Abah M,Aljuhani W,Al-Qahtani H. Compare between the complication of simultaneous and staged bilateral knee replacement at king abdulaziz medical city (kamc) - riyadh. MOJ Orthop Rheumatol. 2016;4(3):84-87. DOI: I0.15406/mojor.2016.04.00I40 
We find a mean $\pm \mathrm{SE}$ of the total days of hospital stay for all the groups was $12.58 \pm .52$, for the simultaneous BTKR patients, the mean \pm SE of hospital stay was $11.05 \pm 0.39$ days, and for the staged was $16.19 \pm 1.31$ days and $9.96 \pm 0.58$ days, with a $p$ value $<.0001$. The mean duration of operation was $2.75 \pm 0.08$ hours, $2.14 \pm 0.06$ hours for the simultaneous, $4.0 \pm 0.13$ hours for the staged and $2.01 \pm 0.09$ for the unilateral. $28.64 \pm 0.98$ is the mean drop of hemoglobin for all the groups, $26.0 \pm 1.12$ simultaneous BTKR, $31.12 \pm 2.13$ was the mean for the staged BTKR and $30.21 \pm 1.97$ for the unilateral. 1.09 \pm 0.09 unites is the mean \pm SE for the blood transfusion for all the groups, $0.527 \pm 0.09$ is the mean for the simultaneous, $2.28 \pm 1.78$ is the mean for the staged and $0.352 \pm 0.12$ is the mean for unilateral group (Table $4)$.

\section{Discussion}

We noticed a female dominance $210(85.71 \%)$ of the patients were female. We find this to be compatible with other study where they had a significant higher proportion of female patients $(\mathrm{P}<.0001) 59 \%$ underwent simultaneous BTRK and 64\% underwent unilateral TKR . ${ }^{1}$

Previous research shows that the increase in age variable for the male results in higher complications rates. ${ }^{1,2}$ In our study, we found that the mean age for patients to undergo total knee replacement is $60.35 \pm 0.39$ years old; whereas, the mean age for another study was 64.1 years old. ${ }^{6}$ We found it was the same as to weight differences between the different groups, with a mean weight of $83.13 \pm 0.79 \mathrm{Kg}$. Another study shows similar findings, they had 32.1 mean of BMI for the different groups. ${ }^{6}$

We had only one patient who needed the admission to the Intensive care Units (ICU), not because she developed any complication, but because she had aortic regurgitation. As a result, she was admitted to the ICU right after the operation.

Another study found the increase of complications with the bilateral TKR when compared to unilateral TKR..$^{3-6}$ Odum et al. ${ }^{1}$ found that there was a high risk of developing complications for a patient who underwent bilateral total knee replacement, where $6.85 \%$ developed minor complications and $1.52 \%$ developed major complications for simultaneous group, $4.60 \%$ of the unilateral patient developed minor complications and $1.20 \%$ developed major complications with a significant $\mathrm{p}$ value, $(\mathrm{p}<.0001) .{ }^{1}$ In our study, none of the unilateral had developed any major complications, and only $15.69 \%$ had developed minor complications.

A significant difference was found between the groups in respect to length of stay, the mean of days for simultaneous BTKR is 11.05 days, 16.19 days for staged and 9.96 days for the unilateral group with a significant $\mathrm{p}$ value of less than $<.0001$. Fabi et al. ${ }^{3}$ study had a mean for unilateral and bilateral groups of 3.3 and 4.9 days, respectively, with a significant $p$ value of less than $0.0001 .{ }^{1}$ Another study had similar findings to this study; the means were 9.6 days for the unilateral group, 16.4 days for the staged group and 14.4 days for the simultaneous group. ${ }^{5}$

\section{Conclusion/Recommendations}

We can say that simultaneous TKR is a save procedure to be performed especially in hospitals where there are long waiting lists, as well as when it is difficult to arrange having elective beds.

\section{Ackowledgments}

None.

\section{Conflicts of interst}

None.

\section{References}

1. Odum SM, Springer BD In-Hospital Complication Rates and Associated Factors After Simultaneous Bilateral Versus Unilateral Total Knee Arthroplasty. J Bone Joint Surg Am. 2014:96(13):1058-1065.

2. Dong $\mathrm{Fu}$, Guodong $\mathrm{Li}$, Kai Chen et al. Comparison of Clinical Outcome Between Simultaneous-Bilateral and Staged-Bilateral Total Knee Arthroplasty: A Systematic Review of Retrospective Studies. J Arthroplasty. 2013:28(7):1141-1147.

3. Fabi DW, Mohan V, Goldstein WM et al. Unilateral vs Bilateral Total Knee Arthroplasty. J Arthroplasty. 2011:26(5):668-673.

4. Levy YD, Hardwick ME, Copp SN Thrombosis Incidence in Unilateral vs. Simultaneous Bilateral Total Knee Arthroplasty with Compression Device Prophylaxis. J Arthroplasty. 2013:28(3):474-478.

5. Poultsides LA, Memtsoudis SG, Vasilakakos T et al. Infection Following Simultaneous Bilateral Total Knee Arthroplasty. $J$ Arthroplasty. 2013:28(8):92-95

6. Ekinci Y, Oner M, Karaman I et al. Comparison of simultaneous bilateral with unilateral total knee arthroplasty. Acta Orthop Traumatol Turc. 2014:48(2):127-135.

7. Singh JA, Kundukulam J, Riddle DL et al.x Early Postoperative Mortality Following Joint Arthroplasty: A Systematic Review. J Rheumatol. 2014:38(7):1507-1513.

8. Leitch KK, Dalgorf D, Borkhoff $\mathrm{CM}$ et al. Bilateral total knee arthroplasty - staged or simultaneous? Ontario's orthopedic surgeons reply. Can J Surg. 2005:48(4):273-276. 